\title{
Special Section Introduction: Thriving in Context: Findings from the 4-H Study of Positive Youth Development
}

\author{
G. John Geldhof • Edmond P. Bowers • \\ Richard M. Lerner
}

Received: 13 July 2012/ Accepted: 2 November 2012/Published online: 9 November 2012

(C) Springer Science+Business Media New York 2012

\begin{abstract}
The positive youth development perspective, a strength-based relational developmental systems model that focuses on mutually influential relationships between individuals and contexts, has been used to study thriving across the second decade of life. However, more attention has been paid empirically to identifying the features of the individual (e.g., intentional self regulation, hope, or purpose) or to enumerating the role of context-general ecological assets than to the nature of individual-context relationships linked to thriving within specific contexts. The goal of this special section is to provide initial research reports about contextspecific instances of the thriving process. The research focuses on two contexts where many youth spend a considerable amount, and often the majority, of their timeschool and out-of-school time sports activities.
\end{abstract}

\section{Introduction}

Multiple dimensions of profound changes are prototypic of the adolescent period, involving levels of organization ranging from the physical and physiological, through the cognitive, emotional, and behavioral, and to the social

The research reported in this special section was supported in part by a grant from the National 4-H Council.

G. J. Geldhof · E. P. Bowers · R. M. Lerner $(\bowtie)$

Institute for Applied Research in Youth Development,

Tufts University, 301 Lincoln Filene Building,

Medford, MA 02155, USA

e-mail: richard.lerner@tufts.edu

G. J. Geldhof

e-mail: john.geldhof@tufts.edu

E. P. Bowers

e-mail: edmond.bowers@tufts.edu relational and institutional. When these changes are systematic, they represent the plasticity inherent in the developmental system (Lerner 1984). Such plasticity represents a fundamental strength of the adolescent period (Lerner 2009), in that it provides the material potential for positive functioning. Indeed, if adaptive developmental regulations (that is, mutually influential relationships between the individual and the context, represented as individual $\leftarrow \rightarrow$ context relationships) emerge or can be fostered between the plastic, developing young person and features of his context (e.g., the structure and function of his/her family, school, peer group, and community), then the likelihood will increase that youth may thrive (that is, manifest healthy, positive developmental changes) across the adolescent decade.

Indeed, predicated on relational developmental systems theory (Overton 2010, 2011; Overton and Müller 2012), the links among plasticity, adaptive developmental regulations, and thriving suggest that all young people have strengths that may be capitalized on to promote thriving across the adolescent years. Through the lens of relational developmental systems theory, it is possible to assert that youth represent "resources to be developed" (Roth and Brooks-Gunn 2003a, b). This strength-based view of adolescents increasingly has been used to study positive youth development (PYD), or thriving, within the United States (e.g., Lerner et al. 2012) and internationally (e.g., Gestsdottir and Lerner 2007; Silbereisen and Lerner 2007). The results of this research has led to the identification of the characteristics of thriving that emerge from this relational process (e.g., the Five Cs of PYD or youth Contribution; J. Lerner et al. in press; Lerner 2009). In addition, research has identified the individual and ecological bases of the development of these characteristics and theoretically expected outcomes of the PYD process, e.g., youth community contribution or active and engaged citizenship (e.g., Zaff et al. 2010). 
However, it is fair to say that, with some exceptions (e.g., see Theokas and Lerner 2006; Urban et al. 2011), more attention has been paid to identifying important features of the individual (e.g., intentional self regulation, hope, or purpose) or to enumerating the role of contextgeneral ecological assets (e.g., Benson et al. 2006, 2011) than to ascertaining the nature of the mutually influential relationships between individual and contexts (represented as individual $\leftarrow \rightarrow$ context relationships) within specific contexts. The goal of this special section is to provide initial research about such context-specific instances of the thriving process. The articles in this special section focus on the two contexts that, together, involve the greatest investment of youth time, the school and out-of-school time sports programs (e.g., Balsano et al. 2009; Elmore 2009; Zarrett et al. 2009).

\section{The Importance of Studying Thriving Within Key} Contexts of Youth Development

Adaptive developmental regulations emerge from the intersection of plastic, developing young people and features of their specific contexts (e.g., the structure and function of their family, school, peer group, or communitybased program). As such, it is important to attend to the context-specific instantiation of the thriving process in order to test whether it is manifested in the same way across the different settings within which youth spend their time. Such a focus helps frame the context-specific study of PYD.

Of course, there are several different theoretical views of the PYD process (e.g., Baltes et al. 2006; Benson 2008; Damon 2004, 2008; Eccles 2004; Eccles and Wigfield 2002; Larson 2000; Lerner 2004, Lerner et al. 2005; Masten 2001; Spencer 2006; see also Lerner et al. 2009). Nevertheless, these conceptions of thriving share, at the metatheoretical level, an emphasis on relational developmental systems thinking and an interest in adaptive individual $\leftarrow \rightarrow$ context relationships. The model of the thriving process used by Lerner and Lerner (e.g., Lerner et al. 2012) explicitly draws on this relational conception. This model frames the research reported in this special section. Accordingly, it is useful to discuss the Lerner and Lerner model and describe the data base they developed to test it.

\section{The 4-H Study of PYD}

The 4-H Study of PYD (e.g., Lerner et al. 2005, 2009, 2010, 2011) seeks to identify the individual and ecological relationships that may promote thriving and that, as well, may have a preventive effect in regard to risk/problem behaviors. Within the 4-H Study, thriving is seen as the growth of attributes that mark a flourishing, healthy young person, for example, the characteristics termed the "Five Cs" of PYD - competence, confidence, character, connection, and caring (Eccles and Gootman 2002; Lerner et al. 2005; Roth and Brooks-Gunn 2003a, b). A key hypothesis tested in this approach to PYD is that, if: (a) the strengths of youth (b) can be aligned with the resources for positive growth found in families, schools, and communities, then (c) young people's healthy development may be optimized (Lerner 2004). In addition, given that positively developing youth should be involved in adaptive developmental regulations, then a thriving young person should act to contribute to the context that is benefiting him or her; there should be contributions to self, family, community, and civil society (Jelicic et al. 2007; Lerner et al. 2005). In other words, if positive development rests on mutually beneficial relationships between the adolescent and his/her ecology, then thriving youth should be engaged positively with and act to enhance their world and should be less prone to engage in risk/problem behaviors. Figure 1 presents an illustration of the Lerner and Lerner conception of the thriving process.

As indicated in the figure, the developmental process envisioned by Lerner and Lerner (e.g., Lerner et al. 2005) to be involved in the thriving process involves adaptive developmental regulations between the strengths of youth and the developmental assets present in their ecologies. These mutually beneficial individual $\leftarrow \rightarrow$ context relationships are depicted as being associated with PYD (and the Five Cs associated with this construct) and, in turn, with the enhanced probability of the contributions of youth to their ecology and with lowered probabilities of risk/ program behaviors. The outcomes of these adaptive developmental regulations feed back to the individual and his/her context and thus create a nonrecursive basis for further adaptive developmental regulations. The figure also illustrates that these adaptive developmental regulations and their positive and problematic sequelae exist within the broader ecology of human development. This ecology includes cultural and historical (temporal) variation, and thus introduces change at all levels of organization within the developmental system (Bronfenbrenner and Morris 2006; Elder 1998). Such changes are manifested by intraindividual change, by interindividual differences in intraindividual change, and by normative and non-normative contextual variation (Baltes et al. 1977).

The process represented in Fig. 1 may be used to summarize the contributions to this special section. These contributions advance research about youth thriving by exploring the features of the process that exist within two of the key contexts of youth development, school and outof-school-time (OST) programs involving youth participation in sports; such participation is the major instance of 


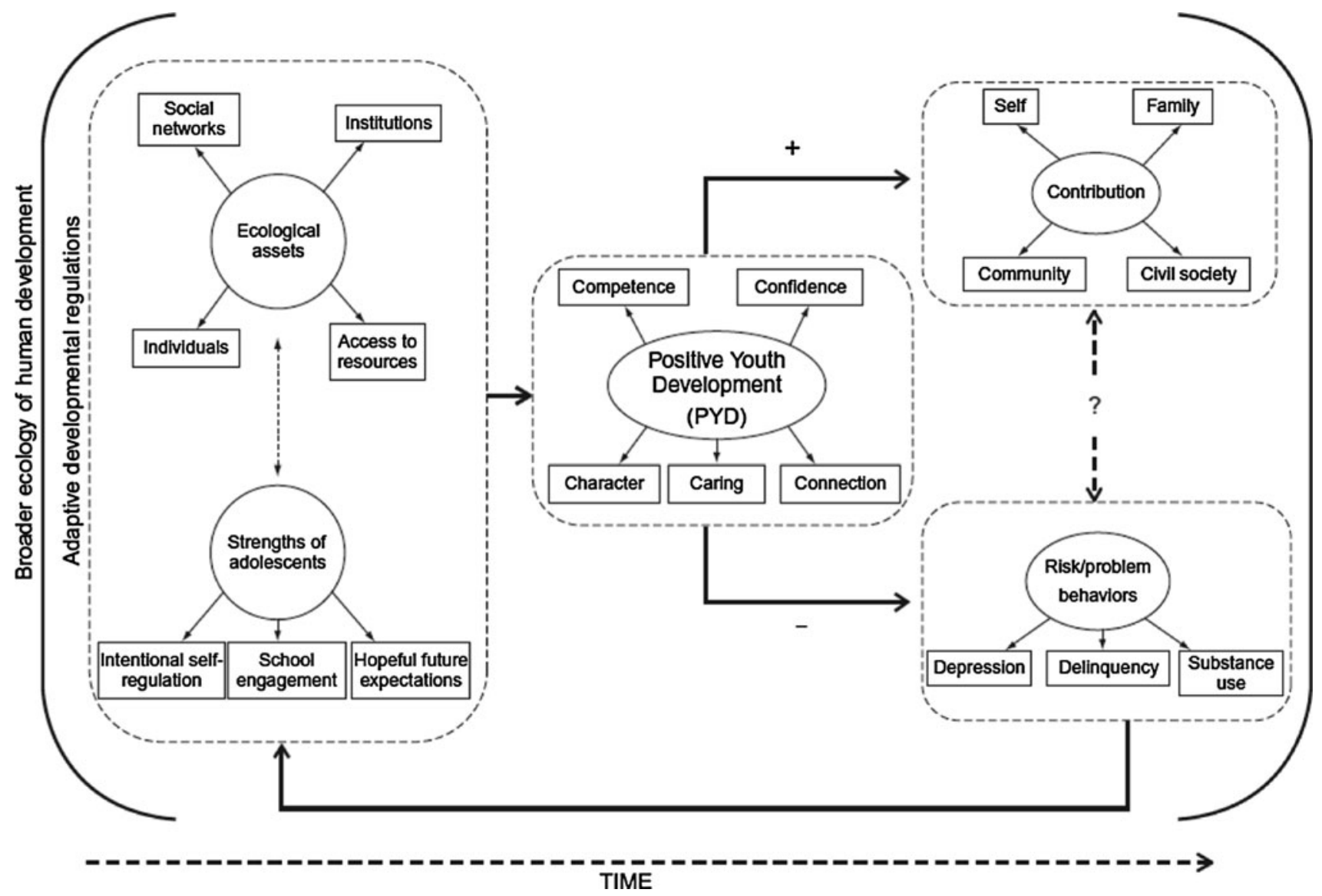

Fig. 1 The relational, developmental systems model of the individual $\leftarrow \rightarrow$ context relations involved in PYD used by Lerner et al. (2005, 2011)

OST activity among youth (e.g., Balsano et al. 2009; Zarrett et al. 2009). Across the articles in this special section, the reported data provide an important means to appraise the nature of the similarities or differences in thriving across key contexts of youth.

\section{An Overview of this Special Section}

The focus of each of the articles in this special section pertains to the features of thriving that accrue in either the school or OST-sport contexts. In the first article in the special section, Lynch and colleagues identified significant links between adolescents' scholastic context and academic outcomes, proposing that within each school there exists a school-wide peer culture that is comprised of two components (a relational and a behavioral component) that are related to individual academic outcomes. The relational component describes students' perceptions of the quality of peer relationships within each school while the behavioral component is an aggregate representation of students' actual behaviors in regard to academic tasks. Using the 4-H Study data set, Lynch and colleagues explored the idea that during adolescence the relational and behavioral components of a school's peer culture are related to students' academic achievement and school engagement. Results suggested that above and beyond a variety of individual, familial, peer, and school characteristics that previously have been associated with academic outcomes, aspects of behavioral peer culture are associated with individual achievement while components of both relational and behavioral peer culture are related to school engagement. Accordingly, this research underscores the admittedly complex contexts of youth in nuanced (and innovative) manners.

$\mathrm{Li}$ and Lerner also studied the school context, focusing on school engagement, or the extent to which students are involved, attached, and committed to the academic and social activities in school. The authors explored the role that school engagement plays in preventing academic failure, promoting competence, and influencing a wide range of adolescent outcomes. Although the multidimensional nature of school engagement is well-recognized, how the three purported parts of the construct work together is largely unknown. By utilizing the 4-H Study data 
set, $\mathrm{Li}$ and Lerner examined the interrelations of behavioral, emotional, and cognitive aspects of school engagement over 3 years in adolescence. Results of autoregressive lagged effects models revealed reciprocal relationships between behavioral and emotional engagement and a unidirectional link between behavioral and cognitive engagement. These findings point to the importance of taking a differentiated and change-sensitive approach to conceptualizing and studying the links between young people and the key contexts of their lives.

In the third article of this special section, Fay and Lerner discuss eating pathology and sports participation patterns among Grade 9 through 11 youth in the 4-H Study data set. The authors tested the idea that sports participation among these youth was a moderator for high versus low-risk eating disorder problems. Fay and Lerner identified several distinct trajectories of adolescents' eating pathology and body dissatisfaction and linked these pathways to both individual and contextual correlates of these pathways. As such, this study highlights that diversity of patterns of intraindividual change in person $\leftarrow \rightarrow$ context links are a ubiquitous feature of positive or problematic youth development.

\section{Conclusions}

The articles in this special section provide support for the use of a relational developmental systems theory-based approach to the thriving process. The research reported in this special section enhances the understanding of the intricacies of context-specific individual $\leftarrow \rightarrow$ context relationships, links that-when mutually beneficial to both individual and context - put young people on a thriving journey across the adolescent period. Moreover, as readers review the scholarship included in these articles, they will find evidence that supports the idea that there is a diversity of youth strengths and ecological developmental assets that may be integrated within and across contexts to foster thriving and enhance the likelihood of the contributions of youth while decreasing the likelihood of risk/problem behaviors.

As the theory-predicated, context-specific research presented in this special section continues to evolve, and as other work pertinent to the study and enhancement of thriving processes continues (e.g., Lerner et al. 2012), developmental science will become increasingly able to specify what sorts of individual and contextual resources need to be linked within specific settings wherein youth live and develop in order to maximize the probability that all young people will be given a greater chance to thrive. As such, and underscoring the vital connection between research and application involved in the PYD perspective
(Hamilton 1999; Lerner et al. 2012), the articles in this special section provide reason for all people concerned with the health and welfare of adolescents to be optimistic that evidence-based actions can be taken to enhance the chances for thriving among all young people.

Acknowledgments GJG helped draft the manuscript, and read and approved the final manuscript. EPB helped draft the manuscript, and read and approved the final manuscript. RML helped draft the manuscript, and read and approved the final manuscript.

\section{References}

Balsano, A., Phelps, E., Theokas, C., Lerner, J. V., \& Lerner, R. M. (2009). Patterns of early adolescents' participation in youth development programs having positive youth development goals. Journal of Research on Adolescence, 19(2), 249-259.

Baltes, P. B., Lindenberger, U., \& Staudinger, U. M. (2006). Lifespan theory in developmental psychology. In R. M. Lerner (Ed.), Theoretical models of human development. Vol. 1: Handbook of Child Psychology (6th ed., pp. 569-664). Editors-in-chief: W. Damon \& R. M. Lerner. Hoboken, NJ: Wiley.

Baltes, P. B., Reese, H. W., \& Nesselroade, J. R. (1977). Life-span developmental psychology: Introduction to research methods. Monterey, CA: Brooks/Cole.

Benson, P. L. (2008). Sparks: How parents can help ignite the hidden strengths of teenagers. San Francisco, CA: Jossey-Bass.

Benson, P. L., Scales, P. C., Hamilton, S. F., \& Semsa, A., Jr. (2006). Positive youth development: Theory, research, and applications. In R. M. Lerner (Ed.). Theoretical models of human development. Volume 1 of Handbook of Child Psychology (6th ed.) (pp. 894-941). Editors-in-chief: W. Damon \& R. M. Lerner. Hoboken, NJ: Wiley.

Benson, P. L., Scales, P. C., \& Syvertsen, A. K. (2011). The contribution of the developmental assets framework to positive youth development theory and practice. In R. M. Lerner, J. V. Lerner, \& J. B. Benson (Eds.). Advances in Child Development and Behavior, 41, 197-230.

Bronfenbrenner, U. \& Morris, P. A. (2006). The bioecological model of human development. In R. M. Lerner (Ed.). Theoretical models of human development. Volume 1 of Handbook of Child Psychology (6th ed.). Editors-in-chief: W. Damon \& R. M. Lerner. Hoboken, NJ: Wiley.

Damon, W. (2004). What is positive youth development? The Annals of the American Academy of Political and Social Science, 591, $13-24$.

Damon, W. (2008). The path to purpose: Helping our children find their calling in life. New York: Simon and Schuster.

Eccles, J. S. (2004). Schools, academic motivation, and stageenvironment fit. In R. M. Lerner \& L. Steinberg (Eds.), Handbook of adolescent psychology (2nd ed., pp. 125-153). Hoboken, NJ: John Wiley \& Sons, Inc.

Eccles, J., \& Gootman, J. A. (Eds.). (2002). Community programs to promote youth development/Committee on Community-Level Programs for Youth. Washington, DC: National Academy Press.

Eccles, J. S., \& Wigfield, A. (2002). Motivational beliefs, values, and goals. Annual Review of Psychology, 53, 109-132.

Elder, G. H., Jr. (1998). The life course and human development. In R. M. Lerner (Vol. Ed.) \& W. Damon (Ed.), Handbook of child psychology: Vol. 1: Theoretical models of human development (5th ed., pp. 939-991). New York: John Wiley.

Elmore, R. E. (2009). Schooling adolescents. In R. M. Lerner \& L. Steinberg (Eds.). Contextual Influences on Adolescent 
Development. Volume 2 of Handbook of Adolescent Psychology (3rd Ed.). Editors-in-chief: R. M. Lerner \& L. Steinberg. Hoboken, NJ: Wiley.

Gestsdottir, S., \& Lerner, R. M. (2007). Intentional self-regulation and positive youth development in early adolescence: Findings from the 4-H Study of Positive Youth Development. Developmental Psychology, 43(2), 508-521.

Hamilton, S. F. (1999). A three-part definition of youth development. Unpublished manuscript, Cornell University College of Human Ecology, Ithaca NY.

Jelicic, H., Bobek, D., Phelps, E. D., Lerner, J. V., \& Lerner, R. M. (2007). Using positive youth development to predict contribution and risk behaviors in early adolescence: Findings from the first two waves of the 4-H Study of Positive Youth Development. International Journal of Behavioral Development, 31(3), 263-273.

Larson, R. W. (2000). Toward a psychology of positive youth development. American Psychologist, 55(1), 170-183.

Lerner, R. M. (1984). On the nature of human plasticity. New York: Cambridge University Press.

Lerner, R. M. (2004). Liberty: Thriving and civic engagement among America's youth. Thousand Oaks, CA: Sage Publications.

Lerner, R. M. (2009). The positive youth development perspective: Theoretical and empirical bases of a strength-based approach to adolescent development. In C. R. Snyder \& S. J. Lopez (Eds.), Oxford handbook of positive psychology (2nd ed., pp. 149-163). Oxford, England: Oxford University Press.

Lerner, J. V., Bowers, E. P., Minor, K., Lewin-Bizan, S., Boyd, M. J., Mueller, M. K., Schmid, K. L., Napolitano, C. M., \& Lerner, R. M. (2012). Positive youth development: Processes, philosophies, and programs. In R. M. Lerner, M. A., Easterbrooks, \& J. Mistry (Eds.), Handbook of Psychology, Volume 6: Developmental Psychology ( $2^{\text {nd }}$ edition). Editor-in-chief: I. B. Weiner. (pp. 365-392). Hoboken, NJ: Wiley.

Lerner, R. M., Lerner, J. V., Almerigi, J., Theokas, C., Phelps, E., Gestsdottir, S., et al. (2005). Positive youth development, participation in community youth development programs, and community contributions of fifth grade adolescents: Findings from the first wave of the 4-H Study of Positive Youth Development. Journal of Early Adolescence, 25(1), 17-71.

Lerner, R. M., von Eye, A., Lerner, J. V., \& Lewin-Bizan, S. (2009). Exploring the foundations and functions of adolescent thriving within the 4-H study of positive youth development: A view of the issues. Journal of Applied Developmental Psychology, 30(5), 567-570.

Lerner, R. M., von Eye, A., Lerner, J. V., Lewin-Bizan, S., \& Bowers, E. P. (2010). Special issue introduction: The meaning and measurement of thriving: A view of the issues. Journal of Youth and Adolescence, 39(7), 707-719.

Lerner, R. M., Lerner, J. V., Bowers, E. P., Lewin-Bizan, S., Gestsdottir, S., \& Urban, J. B. (2011). Self-regulation processes and thriving in childhood and adolescence: A view of the issues. In R. M. Lerner, J. V. Lerner, E. P. Bowers, S. Lewin-Bizan, S. Gestsdottir, \& J. B. Urban (Eds.), Thriving in childhood and adolescence: The role of self-regulation processes. New Directions for Child and Adolescent Development, 133, 1-10.

Masten, A. S. (2001). Ordinary magic: Resilience processes in development. American Psychologist, 56(3), 227-238.

Overton, W. (Ed.). (2010). The handbook of life-span development. Vol. 1: Cognition, biology, methods. Hoboken: Wiley.

Overton, W. F. (2011). Relational developmental systems and quantitative behavior genetics: Alternative of parallel methodologies. Research in Human Development, 8, 258-263.

Overton, W. F., \& Müller, U. (2012). Meta-theories, theories, and concepts in the study of development. In R. M. Lerner, M. A. Easterbrooks, \& J. Mistry (Eds.), Comprehensive handbook of psychology: Developmental psychology (Vol. 6, pp. 19-58). Editor-in-Chief: Irving B. Weiner. New York: Wiley.

Roth, J. L., \& Brooks-Gunn, J. (2003a). What is a youth development program? Identification and defining principles. In. F. Jacobs, D. Wertlieb, \& R. M. Lerner (Eds.), Enhancing the life chances of youth and families: Public service systems and public policy perspectives: Vol. 2 Handbook of applied developmental science: Promoting positive child, adolescent, and family development through research, policies, and programs (pp. 197-223). Thousand Oaks, CA: Sage.

Roth, J. L., \& Brooks-Gunn, J. (2003b). What exactly is a youth development program? Answers from research and practice. Applied Developmental Science, 7, 94-111.

Silbereisen, R. K., \& Lerner, R. M. (Eds.). (2007). Approaches to positive youth development. London: Sage Publications.

Spencer, M. B. (2006). Phenomenology and ecological systems theory. Development of diverse groups. In W. Damon \& R. M. Lerner (Eds.), Handbook of child psychology (6th ed., Vol. 1, pp. 829-893). New York: Wiley.

Theokas, C., \& Lerner, R. M. (2006). Observed Ecological Assets in Families, Schools, and Neighborhoods: Conceptualization, Measurement and Relations with Positive and Negative Developmental Outcomes. Applied Developmental Science, 10(2), 61-74.

Urban, J. B., Osgood, N., \& Mabry, P. (2011). Developmental systems science: Exploring the application of non-linear methods to developmental science questions. Research in Human Development, 8, 1-25. doi:10.1080/15427609.2011.549686.

Zaff, J., Boyd, M., Li, Y., Lerner, J. V., \& Lerner, R. M. (2010). Active and engaged citizenship: Multi-group and longitudinal factorial analysis of an integrated construct of civic engagement. Journal of Youth and Adolescence, 39(7), 736-750.

Zarrett, N., Fay, K., Carrano, J., Li, Y., Phelps, E., \& Lerner, R. M. (2009). More than child's play: Variable- and pattern-centered approaches for examining effects of sports participation on youth development. Developmental Psychology, 45(2), 368-382.

\section{Author Biographies}

G. John Geldhof is a research assistant professor in the Institute for Applied Research in Youth Development at Tufts University. His research emphasizes the integration of diverse theoretical approaches to self-regulation and examines how self-regulation develops across the life span.

Edmond P. Bowers is research assistant professor at the EliotPearson Department of Child Development and director of the Thrive Foundation for Youth's GPS Project at Tufts University. His research focuses on the influence of non-parental caregivers on the life skills development of adolescents.

Richard M. Lerner is the Bergstrom Chair in Applied Developmental Science and the Director of the Institute for Applied Research in Youth Development at Tufts University. He received his Ph.D. in developmental psychology from the City University of New York. His work integrates the study of public policies and community-based programs with the promotion of positive youth development and youth contributions to civil society. 